Jurnal Ilmiah Ibnu Sina, 6(2), Oktober 2021, 252-261

p-ISSN: 2502-647X; e-ISSN: 2503-1902

\title{
POTENSI DARI EKSTRAK DAN FRAKSI KULIT BUAH MUNDAR (Garcinia forbesii) SEBAGAI TABIR SURYA BERDASARKAN NILAI SUN PROTECTION FACTOR (SPF)
}

\author{
Muhammad Ikhwan Rizki ${ }^{1 *}$, Samsul Hadi' ${ }^{1}$, Lutfi Chabib ${ }^{2}$ \\ ${ }^{1}$ Program Studi Farmasi FMIPA Universitas Lambung Mangkurat \\ ${ }^{2}$ Program Studi Farmasi FMIPA Universitas Islam Indonesia \\ *Email: $\underline{\text { khwanrizki@ulm.ac.id }}$
}

\begin{abstract}
Artikel diterima: 13 Juli 2021; Disetujui: 3 September 2021
DOI: https://doi.org/10.36387/jiis.v6i2.716
\end{abstract}

\begin{abstract}
ABSTRAK
Sinar UV dapat menyebabkan kerusakan kulit seperti hilangnya elastisitas kulit, kerutan, kendur, dan menyebabkan kanker kulit.. Kalimantan Selatan sebagai daerah lahan basah terdiri atas lebih dari 4.000 spesies tumbuhan obat.. Tumbuhan mundar (Garcinia forbesii) merupakan salah satu tumbuhan yang tumbuh di daerah Kalimantan Selatan. Kulit buah mundar secara empiris digunakan untuk kosmetika yang dipercaya mampu melindungi kulit dari sinar ultraviolet. Tujuan penelitian ini yaitu mengetahui potensi tabir surya dari ekstrak dan fraksi kulit buah mundar (Garcinia forbesii) berdasarkan parameter Sun Protection Factor (SPF). Proses penelitian dimulai dari pembuatan simplisia, serbuk simplisia, ekstrak, dan fraksi. Ekstrak dan fraksi diuji nilai SPF sebagai parameter potensi tabir surya. Hasil penelitian menunjukan bahwa ekstrak etanol dan fraksi etil asetat memiliki daya proteksi yang lemah, kecuali pada ekstrak dengan konsentrasi 350 ppm, sedangkan fraksi n-heksan memiliki kemampuan daya proteksi yang ekstrim dengan nilai SPF pada rentang 6,51-30,00.

Kata kunci: Garcinia forbesii, Kulit buah, Mundar, Sun Protection Factor (SPF)

ABSTRACT

$U V$ rays cause skin damage such as loss of skin elasticity, wrinkles, sagging, and skin cancer. South Kalimantan is a wetland area with more than 4,000 species of medicinal plants. Mundar (Garcinia forbesii) is one of the plants in South Kalimantan. Mundar pericarp is empirically used for cosmetics which is believed to protect the skin from ultraviolet rays. The purpose of the study was to determine the sunscreen potency of the extract and fraction from pericarp of mundar (Garcinia forbesii) based on the Sun Protection Factor (SPF) parameter. The research started from material drying, making simplicia powder, extraction, and fractions. The extracts and fractions were measured for SPF values using a $U V$-Vis Spectrophotometer. The results showed that the ethanol extract and ethyl acetate fraction had weak protection, while the $n$-hexane fraction had extreme protective power with SPF values in the range of $6.51-30.00$.
\end{abstract}

Keywords: Garcinia Forbesii, Mundar, Pericarp, Sun Protection Factor (SPF)

Muhammad Ikhwan Rizki, dkk | 252 
Jurnal Ilmiah Ibnu Sina, 6(2), Oktober 2021, 252-261

p-ISSN: 2502-647X; e-ISSN: 2503-1902

\section{PENDAHULUAN}

Radiasi ultraviolet terdiri atas UV-A yang memiliki panjang gelombang 320-400 $\mathrm{nm}$ berdampak dapat menembus dermis, sehingga berakibat pada permasalahan pigmentasi. UV-B yang memiliki panjang gelombang 290-320 nm mampu menembus lapisan terluar atau epidermis kulit, sehingga dapat menyebabkan efek langsung berupa kemerahan atau eritema. Radiasi ultraviolet dapat berakibat rusaknya kulit, seperti hilangnya elastisitas kulit, keriput, kendur, dan kanker kulit (Giacomoni \& Rein, 2004). Radiasi ultraviolet yang berlebihan berakibat pada rusaknya kulit yang berhubungan dengan keberadaan radikal bebas, sehingga diperlukan komponen yang mampu melindungi kulit dari radiasi ultraviolet.

Komponen atau zat yang dapat melindungi kulit dari sinar UV yang berlebih disebut tabir surya. Tabir surya dapat disebut juga Sun Protecting Agent. Senyawa yang berasal dari alam dengan kemampuan sebagai tabir surya salah satunya golongan senyawa fenolik. Tabir surya dapat memberi proteksi pada kulit dengan cara menyebabkan penundaan eritema. Kemampuan tersebut diartikan dengan Sun Protection Factor (SPF) (Hassan et al., 2013). Nilai SPF menyatakan kemampuan melindungi kulit yang mencegah terjadinya eritema (Rai \& Srinivas, 2007). Tabir surya pada umumnya berbahan dasar zat sintetik kimiawi. Bahan alam dari tanaman asli Indonesia belum banyak digunakan sebagai tabir surya.

Tumbuhan yang berasal dari alam dapat digunakan sebagai tanaman obat atau kosmetik. Penggunaan bahan alam sangat populer di Indonesia. Penggunaan bahan alam dianggap lebih aman dari bahan sintetik karena memiliki efek samping yang relatif kecil (Sharma et al., 2014). Kalimantan Selatan merupakan daerah lahan basah terdiri lebih dari 4.000 spesies tumbuhan. Tumbuhan tersebut sangat berpotensi digunakan sebagai bahan obat baru (Kepmenkes, 2007). Tumbuhan mundar (Garcinia forbesii) merupakan salah satu tumbuhan yang tumbuh di daerah Kalimantan Selatan. Gubernur Kalimantan Selatan pada tahun 2018 sedang 
Jurnal Ilmiah Ibnu Sina, 6(2), Oktober 2021, 252-261

p-ISSN: 2502-647X; e-ISSN: 2503-1902

mengajukan buah mundar sebagai salah satu tanaman khas Kalimantan Selatan bersama buah kasturi kepada Kementrian Pertanian. Tanaman mundar paling banyak terdapat di Kabupaten Banjar, Kabupaten Hulu Sungai Selatan, dan Kabupaten Hulu Sungai Tengah.

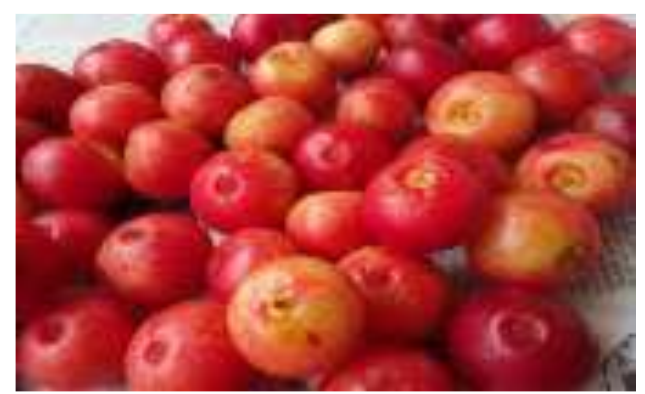

Gambar 1. Buah Mundar $(G$. forbesii)

Tumbuhan $\quad$ G. forbesii menghasilkan buah yang berwarna merah cerah dengan bentuk bundar yang disebut buah mundar (Noor et al., 2015). Buah mundar memiliki karakteristik seperti buah manggis karena satu genus dengan tumbuhan manggis (Garcinia mangostana). Kulit buah $G$. forbesii diketahui mengandung senyawa chromenoxanthone, forbexanthone, pyranojacareubin, dan rubraxhantone (Harrison et al., 1993; Alen et al., 2008). Kulit buah mundar secara empiris digunakan masyarakat untuk kosmetika pada wajah karena warna merah pada kulitnya dipercaya mampu melindungi kulit dari sinar ultraviolet. Tujuan penelitian ini yaitu mengetahui potensi tabir surya dari ekstrak dan fraksi kulit buah mundar (Garcinia forbesii) berdasarkan parameter Sun Protection Factor (SPF).

\section{METODE PENELITIAN}

\section{A. Alat dan Bahan}

Bahan-bahan yang digunakan adalah kulit buah mundar, etanol teknis, kertas saring, n-heksan, etil asetat, aquades, etanol pro analisis.

Alat - alat yang digunakan adalah timbagan analitik, oven, blender, batang pengaduk, tabung reaksi, sudip, erlenmeyer, corong, pipet volumetrik, pipet mikro, cawan porselin, deksikator, rotary evaporator, waterbath, corong pisah, dan spektofotometer UV-VIS.

\section{B. Tahapan Penelitian}

1. Pembuatan serbuk kulit buah mundar

Buah mundar dipanen secara manual dari pohon. Kulit buah mundar berasal dari buah mundar yang telah matang, ditandai dengan 
Jurnal Ilmiah Ibnu Sina, 6(2), Oktober 2021, 252-261

p-ISSN: 2502-647X; e-ISSN: 2503-1902

kulit yang sudah berwarna merah. Kulit buah mundar dibersihkan untuk menghilangkan keberadaan benda asing pada sampel (disortasi basah). Selanjutnya dilakukan pencucian di bawah air mengalir, lalu ditiriskan, dan dirajang. Kulit buah mundar yang sudah dirajang kemudian dimasukan ke dalam oven suhu $50^{\circ} \mathrm{C}$ hingga kering. Selanjutnya setelah kering dilakukan sortasi kering. Sampel yang kering kemudian dihaluskan menggunakan blender hingga menjadi serbuk.

2. Pembuatan ekstrak etanol kulit buah mundar

Serbuk kulit buah mundar direndam dengan pelarut, perbandingan sampel pelarut : etanol $70 \%$ sama dengan 1:10. Serbuk kering kulit buah mundar dimaserasi selama 3 hari. Dilakukan pengadukan setiap 8 jam dan penggantian pelarut setiap 24 jam (Rizki et al, 2021a). Filtrat dipisahkan dengan ampas menggunakan kertas saring. Ekstrak cair dikentalkan menggunakan rotary evaporator pada temperatur $50^{\circ} \mathrm{C}$, lalu diuapkan menggunakan waterbath hingga kental (Rizki et al., 2021b).

\section{Proses fraksinasi}

Ekstrak kental terlebih dahulu disuspensikan menggunakan aquadest dengan perbandingan ekstrak dan aquadest 1:2. Sampel sebanyak 40,0 g disuspensikan dengan $80 \mathrm{~mL}$ aquadest hingga homogen dan dimasukkan ke dalam corong pisah, kemudian ditambahkan $n$-heksan sebanyak $400 \mathrm{~mL}$, dihomogenkan dan digojok selama beberapa menit, dan didiamkan hingga terbentuk pemisahan 2 lapisan yaitu pada bagian atas lapisan $n$-heksan dan pada bagian bawah lapisan air. Fraksinasi dengan $n$-heksan dilakukan sebanyak 10 kali replikasi. Fraksi $n$-heksan dipisahkan dari fraksi air.

Fraksi air dicampurkan pelarut etil asetat sebanyak $400 \mathrm{~mL}$, lalu difraksinasi menggunakan corong pisah, didiamkan kembali beberapa menit sampai terjadi pemisahan 2 lapisan. Lapisan atas yaitu lapisan etil asetat dan lapisan bawah yaitu lapisan air. Fraksinasi dengan etil asetat dilakukan sebanyak 6 kali replikasi. Fraksi tersebut masing-masing dihilangkan pelarutnya menggunakan rotary evaporator dan waterbath.

4. Penentuan nilai SPF 
Jurnal Ilmiah Ibnu Sina, 6(2), Oktober 2021, 252-261

p-ISSN: 2502-647X; e-ISSN: 2503-1902

Penentuan nilai SPF dilakukan secara in vitro menggunakan spektrofotometri UV-Vis. Sampel sejumlah $25 \mathrm{mg}$ dilarutkan dalam 5 $\mathrm{mL}$ etanol p.a, sehingga didapat konsentrasi 5000 ppm. Ambil sebanyak 0,$05 ; 0,1 ; 0,15 ; 0,2 ; 0,3$; $0,35 \mathrm{~mL}$ dari larutan tersebut, dimasukkan pada masing-masing labu ukur $5 \mathrm{~mL}$ dan ditambahkan etanol p.a hingga tanda batas. Konsentrasi dari larutan seri kadar tersebut berturut-turut sebesar 50, 100, 150, 200, 250, 300 dan 350 ppm. Dilakukan pembacaan larutan seri kadar pada panjang gelombang antara 290-320 nm. Pembacaan menggunakan interval $5 \mathrm{~nm}$. Blanko pada pengujian ini menggunakan etanol p.a.

\section{HASIL DAN PEMBAHASAN}

\section{A. Hasil Pembuatan Serbuk Simplisia Kulit Buah Mundar (G. forbesii)}

Pengeringan buah mundar bertujuan mengurangi kandungan air pada simplisia sehingga dapat disimpan dalam jangka waktu yang lama. Kulit buah $G$. forbesii yang sudah dikeringkan dilakukan sortasi kering bertujuan untuk memisahkan kulit buah $G$. forbesii yang rusak selama proses pengeringan maupun zat pengotor lain. Penyerbukan simplisia kering kulit buah $G$. forbesii dilakukan menggunakan blender, hal ini bertujuan untuk memperluas permukaan sampel sehingga dapat memperluas kontak serbuk dengan pelarut saat proses ekstraksi. Serbuk kulit buah $G$. forbesii yang didapat memiliki tekstur yang tidak begitu halus. Hal ini dikarenakan kulit buah G. forbesii mengandung getah yang menyebabkan serbuk menempel pada blender saat proses penyerbukan. Hasil serbuk kulit buah G. forbesii dapat dilihat pada gambar.

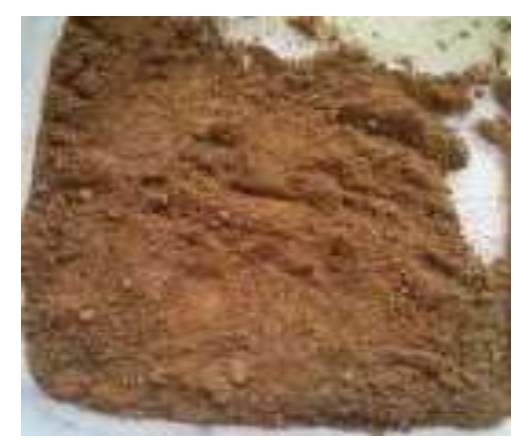

Gambar 2. Serbuk kulit buah mundar (G. forbesii)

\section{B. Hasil Ekstraksi Kulit Buah Mundar}

Ekstraksi kulit buah G. forbesii dilakukan dengan cara merendam 
Jurnal Ilmiah Ibnu Sina, 6(2), Oktober 2021, 252-261

p-ISSN: 2502-647X; e-ISSN: 2503-1902

serbuk simplisia sebesar 50,003 \pm 0,001 gram menggunakan cairan penyari etanol $70 \%$ selama $3 \times 24$ jam pada suhu ruang dengan penyaringan dan penggantian pelarut setiap 24 jam serta dilakukan pengadukan sesekali. Penggunaan etanol $70 \%$ sebagai pelarut dalam proses ekstraksi ini dikarenakan etanol adalah pelarut umum yang dapat lebih banyak menarik senyawa aktif pada suatu bagian tanaman dengan kemampuan penetrasi yang baik untuk menembus dari dinding sel sampel (Yuliani et al., 2011; Patria \& Soegihardjo, 2013; Andayani et al., 2015).

Serbuk kulit buah G. forbesii yang telah diekstraksi menghasilkan ekstrak kental sebanyak 28,410 \pm 0,863 gram. Rendemen yang diperoleh dari ekstrak etanol $70 \%$ kulit buah G. forbesii yaitu sebesar $56,81 \%$. Hasil persen rendemen yang didapat memiliki selisih dengan penelitian Marsella (2018) sebesar $1,02 \%$ yang menyatakan bahwa rendemen ekstrak etanol kulit buah $G$. forbesii yaitu 57,83\%. Hal ini menunjukkan hasil persen rendemen yang tidak jauh berbeda karena memiliki genus dan jenis buah yang sama. Menurut penelitian Pratiwi et al. (2016) ekstrak etanol 70\% kulit buah manggis (Garcinia mangostana) memiliki rendemen sebesar 17,57\%, serta pada penelitian yang dilakukan oleh Dyahnugraha \& Widjanarko. (2015) ekstrak etanol 95\% kulit buah manggis memiliki rendemen sebesar $23,47 \%$. Berdasarkan nilai rendemen yang didapat, kulit buah $G$. forbesii memiliki persentase rendemen yang lebih besar dibandingkan dengan kulit buah G. mangostana.

\section{Hasil Fraksinasi Kulit Buah Mundar}

Ekstrak etanol kental kulit buah G. forbesii sebanyak 10,0 gram difraksinasi menggunakan corong pisah dengan pelarut $n$-heksan. Fraksinasi tersebut menghasilkan dua lapisan yaitu lapisan atas merupakan lapisan $n$-heksan dan pada lapisan bawah merupakan lapisan suspensi air dari ekstrak tersebut. Hal ini disebabkan karena adanya perbedaan berat jenis dari pelarut $n$-heksan yang lebih kecil dibandingkan dengan berat jenis suspensi air. Hasil dari fraksinasi diuapkan dengan cara diangin-anginkan dan menghasilkan fraksi kental sebanyak 0,513 gram. 
Jurnal Ilmiah Ibnu Sina, 6(2), Oktober 2021, 252-261

p-ISSN: 2502-647X; e-ISSN: 2503-1902

Rendemen yang didapatkan dari jumlah senyawa bioaktif yang bersifat fraksi $n$-heksan kulit buah G. forbesii non polar pada tanaman ini lebih yaitu sebesar 5,13\%. Hasil rendemen yang diperoleh lebih besar dibandingkan dengan rendemen fraksi $n$-heksan kulit buah manggis (Garcinia mangostana) yaitu sebesar 0,3174\% (Pratiwi et al., 2016). Hasil rendemen fraksi $n$-heksan kulit buah G. forbesii memiliki nilai rendemen yang lebih rendah dibandingkan fraksi etil asetat kulit buah G. forbesii yang memiliki nilai rendemen sebesar $25,8 \%$. Nilai rendemen yang lebih rendah pada fraksi $n$-heksan kulit sedikit.

\section{Hasil Nilai SPF Ekstrak dan Fraksi Kulit Buah Mundar}

Ekstrak dilarutkan dalam etanol $70 \%$ p.a. dengan konsentrasi 50 ppm, 100 ppm, 150 ppm, 200 ppm, 250 ppm, 300 ppm, 350 ppm dan 400 ppm dibaca pada panjang gelombang 290$320 \mathrm{~nm}$ setiap interval $5 \mathrm{~nm}$. Nilai SPF yang diperoleh dengan data hasil absorbansi menggunakan persamaan Sayre et al. (1979). Hasil dari nilai SPF dapat dilihat pada tabel. buah $G$. forbesii menunjukkan bahwa

Tabel 1. Nilai SPF dari Ekstrak Etanol, Fraksi n-Heksan, dan Fraksi Etil Asetat

\begin{tabular}{lccc}
\hline Sampel & $\begin{array}{l}\text { Konsentrasi } \\
(\mathbf{p p m})\end{array}$ & Nilai SPF & $\begin{array}{l}\text { Kategori } \\
\text { Sinar UV (WHO, 2003)* }\end{array}$ \\
\hline \multirow{4}{*}{ Ekstrak } & 50 & 0,380 & Lemah \\
& 100 & 0,957 & Lemah \\
& 150 & 1,879 & Lemah \\
& 200 & 1,992 & Lemah \\
& 250 & 2,621 & Lemah \\
& 300 & 2,551 & Lemah \\
Fraksi n-Heksan & 350 & 3,024 & Sedang \\
& 50 & 6,51 & Kuat \\
& 100 & 8,84 & Sangat Kuat \\
& 150 & 17,45 & Ekstrim \\
& 200 & 21,83 & Ekstrim \\
& 250 & 27,85 & Ekstrim \\
Fraksi Etil Asetat & 300 & 29,98 & Ekstrim \\
& 350 & 30,00 & Ekstrim \\
\hline 50 & 0,318 & Lemah \\
& 100 & 0,443 & Lemah \\
& 150 & 0,812 & Lemah \\
& 200 & 0,919 & Lemah \\
& 250 & 1,054 & Lemah \\
& 300 & 1,409 & Lemah \\
& 350 & 1,568 & Lemah \\
\hline
\end{tabular}


Jurnal Ilmiah Ibnu Sina, 6(2), Oktober 2021, 252-261

p-ISSN: 2502-647X; e-ISSN: 2503-1902

Hasil pada tabel di atas mangostin berdasarkan data menunjukkan nilai SPF berbanding kromatografi, sedangkan pada fraksi lurus dengan ekstrak atau fraksi yaitu etil asetat tidak terdapat senyawa semakin besar konsentrasi ekstrak tersebut. Diduga senyawa alfa atau fraksi yang ditambahkan, mangostin yang terdapat pada buah semakin meningkatnya nilai SPF. Hal mundar bertanggungjawab terhadap ini berarti ekstrak dan fraksi memiliki kemampuan untuk melindungi kulit dari radiasi sinar matahari. Fraksi nheksan memiliki kemampuan daya proteksi sinar UV paling kuat dibandingkan ekstrak dan fraksi etil asetat. Fraksi n-heksan memiliki kemampuan antioksidan yang paling kuat diantara ekstrak dan fraksi lain (Damayanti, 2019), sehingga diduga memiliki korelasi dengan daya proteksi sinar UV paling kuat disbanding ekstrak dan fraksi etil asetat. Hal tersebut didukung data penelitian lain yang menyatakan bahwa kadar fenolik paling tinggi terdapat pada fraksi n-heksan (Dewi, 2018; Marsella, 2018). Urutan kemampuan proteksi sinar UV dari paling kuat yaitu fraksi n-heksan, ekstrak etanol, dan fraksi etil asetat. Hal tersebut berkorelasi dengan penelitian lain yang menyatakan pada ekstrak dan fraksi n-heksan buah mundar mengandung senyawa alfa daya proteksi sinar UV pada kulit buah mundar. Senyawa alfa mangostin mengandung gugus kromofor sehingga mampu menyerap radiasi dan mengurangi intensitas sinar UV yang mengenai kulit terdalam.

Kemampuan tabir surya ekstrak dan fraksi kulit buah mundar dipengaruhi oleh konsentrasinya. Semakin besar konsentrasi yang digunakan maka kemampuannya dalam memproteksi kulit semakin besar. Hal ini menunjukkan bahwa kandungan berbagai senyawa dalam tumbuhan bertanggungjawab terhadap tinggi rendahnya nilai SPF dari tumbuhan tersebut, sehingga mempengaruhi nilai SPF pada tumbuhan

\section{KESIMPULAN}

Hasil penelitian menunjukan bahwa ekstrak dan fraksi etil asetat memiliki daya proteksi lemah, kecuali 
Jurnal Ilmiah Ibnu Sina, 6(2), Oktober 2021, 252-261

p-ISSN: 2502-647X; e-ISSN: 2503-1902

pada ekstrak dengan konsentrasi 350

ppm, sedangkan fraksi n-heksan

memiliki kemampuan daya proteksi

yang ekstrim dengan nilai SPF pada

rentang $6,51-30,00$.

\section{UCAPAN TERIMA KASIH}

Terimakasih kami ucapkan kepada Dekan FMIPA ULM atas pendanaan penelitian ini melalui Dana DIPA Fakultas MIPA ULM.

\section{DAFTAR PUSTAKA}

Alen, J., Safitri., N. Achriyanus., A. Ladjis., L \& Sargent, 2008, Rubraxhantone dari Garcinia forbesii King. dan Bioaktivitasnya, Jurnal Riset Kimia. 1(2).

Andayani, R., R. Novita \& Verawati, 2015, Pengaruh Metode Ekstraksi Terhadap Kadar Xanton Total dalam Ekstrak Kulit Buah Manggis Matang (Garcinia mangostana L.) dengan Metode Spektrofotometri Ultraviolet. Prosiding Seminar dan Workshop "Perkembangan Terkini Sains Farmasi dan Klinik 5". Padang.

Dewi, A. R., 2018, Penetapan Kadar Fenol dan Tanin Total Serta Uji Aktivitas Antioksidan Metode Frap pada Ekstrak Etanol Kulit Buah Mundar (Garcinia forbesii King.), Skripsi. Fakultas Matematika dan Ilmu Pengetahuan Alam, Universitas
Lambung
Mangkurat,
Banjarbaru.

Dyahnugraha, A. A \& S. B. Widjanarko, 2015, Pemberian Ekstrak Bubuk Simplisia Kulit Manggis (Garcinia mangostana L.) Menurunkan Kadar Glukosa Darah pada Tikus Putih (Rattus norvegicus) Strain Wistar Jantan Kondisi Hiperglikemik, Jurnal Pangan dan Agroindustri, 3: 113-123.

Giacomoni, P. U. \& G. Rein., 2004, A Mechanistic Model for the Aging of Human Skin, Micron. 35: $179-184$

Harrison, L., L. Sia., G. Sim \& K. Tan, 1993, Xanthones from Garcinia forbesii, Phytochemistry, 33(3): 7277281

Hassan, I., K. Dorjay, A. Sami, \& P. Anwar, 2013, Suncreens and Antioxidant as Photo-Protective Measures: An Update, Our Dermatol Online, 4: 369-374.

Kepmenkes, 2007, Kebijakan Obat Tradisional Nasional Tahun 2007, Keputusan Menteri Kesehatan Republik Indonesia Nomor 81/Menkes/SK/III/2007, Kementrian Kesehatan RI, Jakarta

Marsella, C., 2018, Penetapan Kadar Fenol Dan Tanin Total Serta Uji Aktivitas Antioksidan Fraksi Etil Asetat Kulit Buah Mundar (Garcinia Forbesii King.) Dengan Metode Frap, Skripsi, Fakultas Matematika dan Ilmu Pengetahuan Alam, Universitas Lambung Mangkurat, Banjarbaru. 
Jurnal Ilmiah Ibnu Sina, 6(2), Oktober 2021, 252-261

p-ISSN: 2502-647X; e-ISSN: 2503-1902

Patria, W. D \& C. J. Soegihardjo, 2013, Uji Aktivitas Antioksidan Menggunakan Radikal 1,1Difenil-2-pikrilhodrazil (DPPH) dan Penetapan Kandungan Fenolik Total Fraksi Etil Asetat Ekstrak Etanolik Daun Benalu (Dendrophthoe pentandra L. Miq) yang Tumbuh di Pohon Kepel (Stelechocarpus burahol (BI.) Hook. F.), Jurnal Farmasi Sains dan Komunitas, 10: 5160.

Pratiwi, L., A. Sudholi., R. Martien \& S. Pramono, 2016, Ekstrak etanol, Ekstrak etil asetat, Fraksi etil asetat, dan Fraksi nheksan Kulit Manggis (Garcinia mangostana L.) Sebagai Sumber Zat Bioaktif Penangkal Radikal Bebas, Journal of Pharmaceutical Science and Clinical Research. 1: 71-82.

Rai, R. \& C. R., Srinivas, 2007, Photoprotection, Indian Journal Dermatology, Venereology, and Leprology. 73: 73-79.

Rizki, M.I, Nurlely, Fadlilaturrahmah, Ma'shumah, 2021, Aktivitas Antioksidan Ekstrak Etanol Daun Cempedak (Artocarpus integer), Nangka (Artocarpus heterophyllus), dan Tarap (Artocarpus odoratissimus) Asal Kalimantan Selatan, Journal of Current Pharmaceutical Science, Vol. 4 No. 2 (Maret, 2021), 367-372.

Rizki, M.I, Nurlely, Fadlilaturrahmah, Ma'shumah, 2021, Skrining Fitokimia dan Penetapan Kadar Fenol Total Pada Ekstrak Daun Daun nangka (Artocarpus heterophyllus), cempedak (Artocarpus integer), dan tarap (Artocarpus odoratissimus) Asal Desa Pengaron Kabupaten Banjar, Jurnal Insan Farmasi Indonesia, 4(1) Mei 2021 (95102)

Sayre, R. M., P. P. Agim, G. J. Levee \& E. Marlowe, 1979, Comparison of In Vivo and In Vitro Testing of Sunscreeening Formulas, Journal of Photochemical and Photobiology Oxford, 29: 559566.

Sharma, P., Bhardwaj, P., Arif, T., Khan, I., Singh, R., 2014. Pharmacology, Phytochemistry and Safety of Aphrodisiac Medicinal Plants: A Review, RRJPTS, Volume 2, Issue 3

Yuliani, N., A. Syawaalz \& M. Lisna., 2011, Ekstraksi dan Identifikasi Pendahuluan Golongan Senyawa Fenol dari Rimpang Lengkuas Merah (Alpinia purpurata (Vieill) K. Sch), Jurnal Sains Natural Universitas Nusa Bangsa, 1: 111-118. 